\title{
Ecology and restoration techniques for Sargassum beds in Japan
}

\author{
TOSHINOBU TERAWAKI, ${ }^{1}$ KOJI YOSHIKAWA, ${ }^{1}$ GORO YOSHIDA, ${ }^{1}$ SHOGOARAI, ${ }^{2}$ YASUSHI NAKAJIMA ${ }^{3}$ and NOBORU MURASE ${ }^{4}$ \\ 'National Research Institute of Fisheries and Environment of Inland Sea, Fisheries Research Agency, 2-17-5 Maruishi, \\ Hiroshima 739-0452, Japan (crawthitivafficgo.jp), ${ }^{2}$ Marine Algae Research Co., Ltd., 3-9-4 Minatozaka, Fukuoka \\ 811-0114, Japan, ${ }^{3}$ Sanyo Techno Marine Co., Ltd., 1-3-17 Horidome, Tokyo 103-0012, Japan, ${ }^{4}$ National Fisheries \\ University, Fisheries Research Agency, Nagatahonmachi, Yamaguchi 759-6595, Japan
}

SUMMARY: In a number of coastal areas of Japan, many naturally occurring Sargassum beds have been severely damaged or reduced due to land reclamation and water pollution. In order to achieve sustainable coastal development, Sargassum bed restoration has been emphasized as a conservation method. New techniques for restoration include: 1) periodic re-transplanting, supported by artificial production of young plants, is effective to form suitable seascapes in severely polluted and sparsely vegetated areas; 2) transplanting or seeding on artificially provided hard substrata are effective in extending nursery and fishing grounds around existing natural beds; and, 3) restoration of shallow and gently sloping sea bed is effective in creating maintenance-free beds along developed coastlines.

\section{KEYWORDS: ecology, maintenance-free, restoration techniques, Sargassum beds, transplantation}

\section{INTRODUCTION}

The brown macroalga, Surgassum forms the most dominant and important seaweed beds around Japan. However, the area of natural Sargassum beds has been decreasing for many reasons and restoration is becoming an urgent problem. In this presentation, the ecological aspects of naturally occurring Sargassum beds and new techniques for their restoration are reviewed from the point of view of environmental conservation and coastal management.

\section{ECOLOGICAL ASPECTS OF SARGASSUM BEDS}

Sargassum beds are abundant on rocky bottoms along coastal areas of Japan affected by warm currents, particularly the Tsushima Warm Current in the Japan Sea and Seto Inland Sea, southwesterm Japan. ${ }^{1)}$ The area of Sargassum beds has been estimated as 54,000 ha. ${ }^{2)}$ The vertical distribution pattems of Sargassum were found to vary with water depth and intensity of wave action. On the coast of westem Kyushu Is. facing the Eastem China Sea, several species of Sargassum plants are found attached to rocky substrata. ${ }^{3)}$ On the coast of central Honshu Is., facing the Pacific Ocean, the dominate seaweed species changed from shallow to deep water, e.g. several species of Sargassum - Eisenia bicyclis - Ecklonia cava. ${ }^{4)}$ On the coast of central Honshu Is., facing the Sea of Japan, the dominant species were several Sargassum Sea grass and coralline red algae - Ecklonia kurome. ${ }^{5}$ On the coast of westem Honshu Is., facing the Seto Inland Sea, the dominant species were changed in order Sargassum - Ecklonia kurome found at relatively shallow depth.")

Sargassum beds are found on deeper and more stable substrata than Laminaria beds ${ }^{\text {7 }}$ and shallower and less stable substrata than Eisenia / Ecklonia beds. ${ }^{8)}$ The structure of the animal community, e.g. the interaction between the resident fishes and their food sources, associated with Sargassum beds were studied using a basket quadrat and dredges. ${ }^{9)}$ The abundance and species composition of resident fish were assessed in the artificial Sargassum bed using several fishing methods. ${ }^{101}$ Captured fish were classified into the same three groups as from natural Sargassum beds, e.g. migratory fish, aborigines and rocky reef fish groups. ${ }^{1())}$ The biomass of phytal animals in the Sargassum beds varied according to the plant size, density and species diversity of the natural and artificial beds. ${ }^{11)}$ 


\section{DECREASE OF SARGASSUM BEDS}

Since the 1960 's, more than 100,000 ha of coastal land has been reclaimed to increase new commercial and industrial areas. This resulted in a sacrifice of the coastal ecosystem, and a decrease in a natural Sargassum beds. ${ }^{12)}$ The ratio of natural sea coast decreased rapidly to $55 \%$ for the whole Japanese seacoast line, to over $80 \%$ in the Tokyo, Osaka and Hiroshima Bay regions. ${ }^{13)}$ Since the 1970 's, barren grounds, called "Isoyake" areas in Japanese, have arisen in many coastal areas. "Isoyake" areas are considered to be a form of "deforestation" of the sea, caused by intensive grazing by herbivorous animals. ${ }^{14)}$ In these areas, Sargassum beds have declined and have not recovered naturally.

In the 1970's, technical studies on the restoration of rich Sargassum beds in "Isoyake" areas were initiated. ${ }^{15)}$ In the 1980's, technical studies investigated the re-establishment of natural coastal ecosystems to compensate for Sargassum beds destroyed or reduced through construction of reclaimed land. In the 1990's, artificial Sargassum bed creation was adopted by most coastal developmental projects, e.g. ports, fishing ports, breakwaters, formation of new agricultural land and new fisheries grounds. Recently, Sargassum bed restoration became an important aspect of environmental conservation and coastal zone management. ${ }^{15}$

\section{NEW TECHIQUES FOR RESTORATION}

Techniques for Sargassum bed restoration have been developed by application of the principles of seaweed cultivation using ropes and culture nets from the sea-surface to the sea-bottom. ${ }^{16)}$ The principal purposes related to Sargassum bed restoration in Japan have been classified into three categories, ${ }^{17}$ e.g. 1) Cultivation of human food; 2) Propagation of benthic fishery resources; and 3) Increasing fish resources in a management-free style.

\section{1) PERIODIC RE-TRANSPLANTING}

Periodic re-transplanting, supported by artificial production of young plants, is effective to form a suitable seascape in severely polluted and sparsely vegetated areas. A germination rate of $>80 \%$ and healthy growth in outdoor cultivation of $S$. horneri embryos was observed after storage at $5{ }^{\circ} \mathrm{C}$ for one year. ${ }^{18)}$ Healthy, rapid growth and maturation of adventive embyos from $S$. macrocarpum was observed in outdoor culture tanks. ${ }^{19)}$

'Nursery substratum' made from concrete plate fragments were useful for transplanting artificially seeded Sargassum juveniles onto rocky bottoms and coastal structures. ${ }^{2(1)}$ 'Seaweed transplanting plates' made from concrete plate fixed by stainless bolts were useful for re-transplanting of both artificially seeded young plants and mature mother plants which had been artificially attached. $^{21)}$

\section{2) PROVISION OF SUBSTRATA}

Transplants on to artificially provided growing substrata is an effective method to extend nursery and fishing grounds around natural beds. The complete growth cycle (germination, growth, reproduction and death) of transplanted perennial Sargassum plants was observed on concrete blocks set on to a sandy bottom around a natural Sargassum bed. ${ }^{22)}$ Experimental and ecological information has been obtained on the effect of the shape $^{23)}$ and time (season) of placement ${ }^{24)}$ of artificial substrata and the effect of harvest ${ }^{11)}$ on community organization on subtidal concrete blocks set around natural Sargassum beds.

\section{3) RESTORATION OF SHALLOW BOTTOM}

Restoration of shallow and gently sloping bottom substrata is effective in the creation of maintenance-free beds along developed coastlines. The technical points of management-free techniques for Sargassum bed creation are as follows: understanding the principal limiting factors to the local distribution of natural Sargassum plants, and reduction of a limiting factor at the actual site by coastal engineering. In such techniques, transplantation of plants is not required. Transplantation may be undertaken to accelerate growth of the Sargassum population. ${ }^{17}$

However, information required for the establishment of "management-free techniques" for restoration of Sargassum beds, based on controlling ecological succession, is sparse. Experimental structures were placed at 8 depths on the sandy sea bottom off the westem Seto Inland Sea. ${ }^{25)}$ The blocks were structured as in a "stair reef" design with 6 heights above the sandy substratum. ${ }^{15)}$ The succession of algal vegetation at each depth was affected due to subtle differences in light intensity (depth) and sand action (height from sandy 
bottom). ${ }^{15)}$ It has been suggested that Sargassum beds in various phases of establishment would be useful for restoration since their succession might be manipulated using the "stair reef" of various heights above a sandy substratum. ${ }^{15)}$

Gently sloping, shallow sea bottoms should be created to promote ecological succession on new substrata. Over the long term, Sargassum beds on artificial rocky structures and sea grass beds on sandy bottoms develop to form natural habitats which continue in to a maintenance-free state. ${ }^{26)}$

\section{A FORM OF COASTAL ZONE MANAGEMENT}

Off the southwest coast of Hokkaido Is., northern Japan, barren grounds have been caused by intensive sea urchin grazing. ${ }^{27}$ Two methods of restoration were proposed in the "Isoyake" area: 1) seasonal control of excess grazing pressure using fences and, 2) adjustment of depth using blocks and stone to remove urchins by increasing the current velocity by waves. ${ }^{2 \pi}$ Off the south-west coast of Japan, "Isoyake" caused by sea urchin and herbivorous fish has become remarkably widespread, ${ }^{28-3(1)}$ even artificially established kelp beds were destroyed. ${ }^{31)}$ Restoration of Laminaria beds by systematic fishing of sea urchins is possible permission. Management of fishing grounds should be attempted in order to restore damaged seaweed beds.

It is important to make joint plans for coastal environment restoration within specific site, e.g. 1) restoration of shallow sea beds; 2) increase transparency by water quality purification; 3) fishing ground management; 4) undersea "green zone" management by the various environment industries (Fig.1).

\section{ACKNOWLEDGEMENTS}

The authors thank Professor M. Ohno, Kochi University, for many useful suggestions in the preparation of this manuscript. The authors also thank Dr. Alan T. Critchley, Research Center of Degussa Texturant Systems, for many useful suggestions in editing this manuscript.

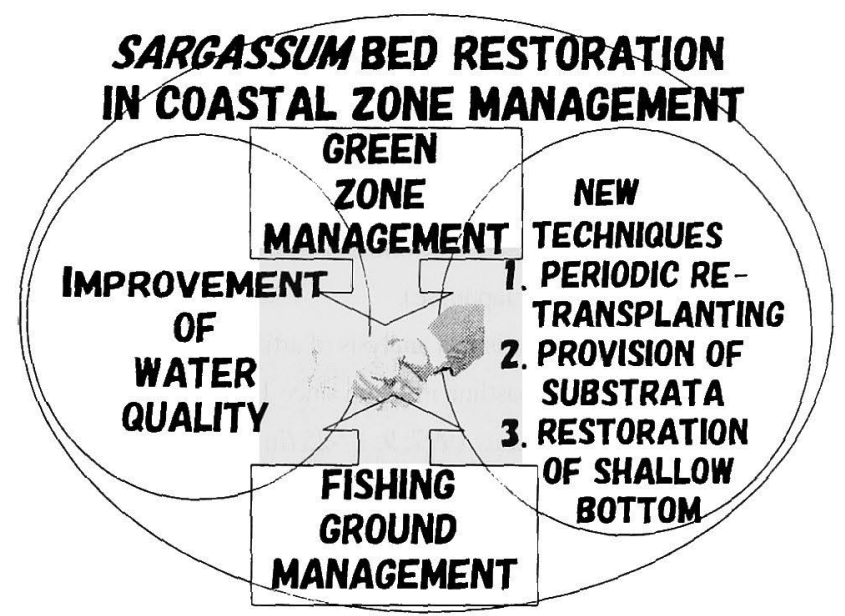

Fig1. Joint efforts for Sargassum bed restoration. ${ }^{32)}$

\section{REFERENCES}

1. Arai S. Hosoya S. Fujii M. Natural history of seaweed beds. Anima 1992; 239: 48-53 (in Japanese).

2. Nature Conservation Bureau, Environmental Agency and Marine Parks Center of Japan. Algal and seagrass beds. The report of the marine biotic environment survey in the 4th survey on the natural environment, Vol. 2, 1994, pp. 1400 (in Japanese with English summary).

3. Yoshida T. Sawada T. Higaki M. Sargassum vegetation growing in the sea around Tsuyazaki, north Kyushu, Japan. Pacific Science 1963; 17: 135-144.

4. Konno T. Vegetation structure of Sargassum and Ecklonia beds. Kaiyo-kagaku 1985; 17: .57-65 (in Japanese).

5. Konno T. Nakajiama Y. Algal vegetation around Goshiki-hama beach, Tango Peninsula. Rep. Marine Park Center 1980; 69: 23-52 (in Japanese).

6. Terawaki T. Yoshikawa K. Yoshida G. Uchimura M. Arai S. Horizontal and vertical distribution pattern of macro-algae in Hiroshima Bay, Western Seto Inland Sea. Bull. Fish. Environ. Inland Sea 2001; 3: 73-81(in Japanese with English summary).

7. Terawaki T. Arai S. Schematic seascapes on sea grass and seaweed beds. 2. Off Chirippu, Hamanaka, Akkeshi, Hokkaido. Jap. J. Phycol. 1999; 47: 233-236 (in Japanese).

8. Terawaki T. Arai S. Schematic seascapes on sea grass and seaweed beds. 3. Off Ogashima Is., Akiya, Yokosuka, Kanagawa Pref. Jap. J. Phycol. 2000; 48: 33-36 (in Japanese).

9. Fuse S. The animal community in the Sargassum belt. Seiri Seitai 1962; 11: 23-45 (in Japanese with English summary)

10. Matsunaga H. Funae K. Usuki H. On the fish assemblages in the man-made Sargassum forest investigated by several fishing methods. Bull. Nanasei Natl. Fish. Res. Inst. 1992; 25: $21-42$ 
(in Japanese with English summary)

11. Yamamoto T. Hamaguchi M. Yoshikawa K. Terawaki T.

Determine factors of community organization in some artificial

Sargassum beds with different vegetation. Fisheries

Engineering 1999;36:1-10(in Japanese with English summary).

12. Isobe M. Creation of coastal environment. Asakura-shoten,

Tokyo, 1994, pp.1-208(in Japanese).

13. Shikida A. Koarai M. Statistical analysis of artificial

modification of natural coastline in Japan since 1960.J. Jap.

Assoc. Coastal Zone Studies 1997; 9: 17-25 (in Japanese).

14. Harrold C. Pears JP. The ecological role of echinoderms in kelp forest. Echinoderms Study, vol.2, A.A.Bolkema, Rotterdam,

Netherlands, 1987, pp.1-320.

15. Terawaki T. Yoshida G. Yoshikawa K. Arai S. Murase N.

"Management-Free" techniques for the restoration of Sargassum

beds using subtital, concrete structures on sandy substratum along

the coast of the westem Seto Inland Sea, Japan. Environmental

Sciences 2000; 7 : 165-175.

16. Yamauchi, K.1984. Studies on the formation of natural and artificial seaweed beds- $V$ The formation of Sargassum beds on artificial substrata by transplanting seedlings of $S$ patens

C.Agardh. Bull. Hyogo Pref. Fish. Exp. Stn. 1984; 22: $67-77$ (in Japanese with English summary)

17. Terawaki T. Arai S. Kawasaki Y. Methods of submarine forest formation considering local limiting factors of distribution.

Fisheries Engineering 1995; 32: 145-154 (in Japanese with English summary).

18. Yoshida G. Yoshikawa K. Terawaki T. Germination rate and growth of Sargassum homeri embryos stored for a long term under low temperature. Nippon Suisan Gakkaishi 2000; 66: 739-740 (in Japanese with English summary).

19. Yoshida G. Yoshikawa K. Terawaki T. Artificial seedlings of Sargassum macrocarpum developed from adventive embryos. Fisheries Science 2001; 67: 352-354.

20. Kito H. Murase N. Marine afforestation system using artificial seeds grown on nursery concrete fragments. Nori and Sea Vegetables 1999; 58: 7-11 (in Japanese).

21.Nakajima Y. Seaweed bed restoration by using of 'Seaweed transplanting plate', Seizando, Tokyo. (in press)

22. Yoshikawa K. Studies on the formation of Sargassum beds. II

The growth of three Sargassaceae by placed blocks on the bottom with artificial seedlings and transplanted by matured plants. Bull.
Nansei Reg. Fish Res. Lab. 1986; 20: 137-146 (in Japanese with English summary).

23. Ohno M. Arai S. Watanabe M. Seaweed succession on artificial reefs on different substrata. J. Appl Phycol. 1990; 2: 323-332.

24. Serisawa Y. Taino S. Ohno M. Anga.Y. Succession of seaweeds on experimental plates immersed during different seasons in Tosa Bay, Japan. Bot. Mar. 1998; 41: 321-328.

25. Terawaki T. Yoshida G. Yoshikawa K. Arima S. Observation on Sargassum vegetation in relation to substratum height above the sea bottom in the westem Seto Inland Sea. Bull. Nansei Natl. Fish. Res. Inst., 1996; 29: 49-58 (in Japanese with English summary).

26. Terawaki T. Dan A. Moriguchi A. Kawasaki Y. Okada, M.Technical review on Zostera bed restoration in Japan. Proceedings of the $2^{\text {ndt }}$ joint meeting, The coastal environmental science and technology panel of the United States-Japan cooperative program in natural resources, 216-230.

27. Kuwahara H. Kawai K. Kaneta T. Mechanisms for kelp foresi development on the barren ground along the southwest coat of Hokkaido, Japan. Fisheries Engineering, 2001;38 (in press, in Japanese with English summary).

28. Shimizu H. Watanabe K. Arai S. Terawaki T. Environmental conditions of locations for Ecklonia kurome Okamura at the coasts of Hyuga-Nada, southern Japan. Rep. Miyazaki Pref. Fish. Exp. Stn. 1999; 7: 29-41 (in Japanese).

29. Kiriyama T. Fujii A. Yoshimura T. Kiyomoto S. Yotsui T. Leaf-lost phenomenon observed on three Laminariaceous species in coastal waters around Nagasaki Prefecture in Autumn 1998. Suisanzoushoku 1999; 47: 319-323 (in Japanese with English summary).

30. Kiyomoto S. Yoshimura T. Arai S. Kiriyama T. Fujii A. Yotsui

$\mathrm{T}$. Grazing selectivity of herbivorous fishes on five macroalgae in sublittoral zone at Nomozaki, Nagasaki Prefecture. Bull.Seikai

Nail Fish. Res. Inst. 2000; 78: 67-75 (in Japanese with English summary).]

31. Masuda H. Tsunoda T. Hayashi Y. Nishio S. Mizui H.

Horiuchi S. Nakayama K. Decline of afforested Ecklonia cava community by grazing of herbivorous fish Siganus fuscescers. Fisheries Engineering 2000; 37: 135-142 (in Japanese with English summary).

32. Terawaki T. Yoshida G. Yoshikawa K. Restoration of sea grass and seaweed beds Kowan 2000; 77: 34-37 (in Japanese). 